\title{
Lipid Profile and Carotid Intima-Media Thickness in a Prospective Cohort of Very Preterm Subjects at Age 19 Years: Effects of Early Growth and Current Body Composition
}

\author{
MARTIJN J.J. FINKEN, AKIN INDERSON, NADINE VAN MONTFOORT, MANDY G. KEIJZER-VEEN, \\ ANTON W.M. VAN WEERT, NERMIN ÇARFIL, MARIJKE FRÖLICH, ELYSÉE T.M. HILLE, JOHANNES A. ROMIJN, \\ FRIEDO W. DEKKER, AND JAN M. WIT ON BEHALF OF THE DUTCH POPS-19 COLLABORATIVE STUDY GROUP
}

\begin{abstract}
Department of Pediatrics [M.J.J.F., J.M.W.], Department of Clinical Epidemiology [M.J.J.F., A.I., N.M., M.G.K.-V, F.W.D.], Department of Clinical Chemistry [M.F.], Department of Endocrinology and Metabolic Diseases [J.A.R.], Leiden University Medical Center, 2300 RC Leiden, The Netherlands; Department of Pediatric Nephrology [M.G.K.-V.], Erasmus MC, Sophia Children's hospital, University Medical Center, 3000 CB Rotterdam, The Netherlands; Heart Core BV [A.W.M.W., N.C.], 2333 AA Leiden, The Netherlands;
\end{abstract} TNO Quality of Life [E.T.M.H.], 2301 CE Leiden, The Netherlands

\begin{abstract}
Cardiovascular disease (CVD) risk is associated with prenatal and infancy growth. However, the relative importance of these time periods for the CVD risk is uncertain. To elucidate this, we tested in a very preterm cohort the effects of birth weight for gestational age and weight gain between birth and 3 mo post-term (early postnatal weight gain) and between 3 mo and 1 y post-term (late infancy weight gain) on the lipid profile and carotid intimamedia thickness (CIMT) at age $19 \mathrm{y}$. A less favorable lipid profile was strongly associated with higher current body mass index (BMI), greater waist circumference, and greater absolute fat mass. CIMT was positively associated with current height, and with low-density lipoprotein (LDL) cholesterol and apolipoprotein B (ApoB) levels, and LDL/high-density lipoprotein (HDL) cholesterol and ApoB/ apolipoprotein AI (ApoAI) ratios. Lipid profile and CIMT were unrelated to gestational age, birth weight standard deviation score (SDS) and early postnatal weight gain. CIMT was positively associated with late infancy weight gain, but the relationship disappeared after correction for current height. Our findings in $19 \mathrm{y}$ olds born very preterm argue for an effect of current body composition, rather than of early growth, on the CVD risk. Attempts to reduce the CVD risk in this specific population should focus on weight reduction in young adulthood rather than on optimizing the early growth pattern.
\end{abstract}

(Pediatr Res 59: 604-609, 2006)

$\mathrm{T}^{\mathrm{s}}$ he "fetal origins of adult disease" hypothesis postulates that CVD has its origin in early life, when specific insults during critical periods in development may permanently alter a body's structure and metabolism (1). Epidemiologic studies

Received July 27, 2005; accepted November 21, 2005

Correspondence: Martijn J. J. Finken, M.D., Department of Pediatrics, Leiden University Medical Center, P.O. Box 9600, 2300 RC Leiden, The Netherlands; e-mail: m.j.j.finken@lumc.nl

This specific part of the POPS-19 study was supported by a grant from the Netherlands Organisation for Scientific Research (NWO). The POPS-19 study was supported by grants from the Netherlands Organisation for Health Research and Development (ZonMw), Edgar Doncker Foundation, Foundation for Public Health Fundraising Campaigns, Phelps Foundation, Swart-van Essen Foundation, Foundation for Children's Welfare Stamps, TNO Quality of Life, Netherlands Organisation for Scientific Research (NWO), Dutch Kidney Foundation, Sophia Foundation for Medical Research, Stichting Astmabestrijding, Royal Effatha Guyot group.

DOI: 10.1203/01.pdr.0000203096.13266.eb have provided evidence of this hypothesis by reporting an inverse association between birth weight and mortality from CVD (2), nonfatal cardiovascular events (3), and the degree of carotid stenosis assessed by intima-media thickness (IMT) (4). Also, it has been demonstrated in elderly men that slow growth until $1 \mathrm{y}$ of age after low birth weight amplified risk of coronary artery disease (5). In contrast, others have shown in boys and girls aged 13-16 y who were born prematurely that rapid instead of slow weight gain in the first two postnatal weeks was associated with decreased brachial flow-mediated dilation (FMD), an early marker of the atherosclerotic process (6). Thus, in early life, at different stages of development, rapid growth and slow growth have been associated with increased CVD risk.

An atherogenic lipid profile is one of the major risk factors for CVD and is characterized by high levels of total cholesterol (TC), LDL cholesterol, triglycerides (TGs), and ApoB, and low levels of HDL cholesterol and ApoAI (7). In a number of studies in individuals born after full-term gestation, birth weight has shown weak associations with some lipid levels [systematically reviewed in Lauren et al. (8) and Huxley et al. (9)].

As fetal weight gain reaches its maximum between 32 and $38 \mathrm{wk}$ of gestation, the circumstances in the third trimester of pregnancy contribute to most of the variation in birth weight. Detrimental circumstances resulting in intrauterine growth retardation can occur early and/or late in gestation. Persons who were in utero in the first trimester of pregnancy during the Dutch famine had the highest prevalence of coronary artery disease and also the highest LDL/HDL ratio $(10,11)$, implying that insults during early gestation predispose to increased CVD risk. Whether lower birth weight for gestational age after the first two trimesters of pregnancy could

\footnotetext{
Abbreviations: ApoAI, apolipoprotein AI; ApoB, apolipoprotein B; CCA, common carotid artery; CIMT, carotid intima-media thickness; CVD; cardiovascular disease; SDS, standard deviation score; TC, total cholesterol; TGs, triglycerides
} 
explain increased CVD risk can only be answered by studies in subjects born very preterm ( $<32$ wk of gestation).

We provide prospective long-term follow-up into adulthood of a well-described cohort of men and women born very preterm in whom lipid levels and CIMT were measured at the age of $19 \mathrm{y}$. Within this study population, we tested the relative importance of the effects of birth weight for gestational age and postnatal weight gain until the age of $1 \mathrm{y}$ post-term on the lipid profile and CIMT in young adulthood. Weight at birth and at the ages of 3 mo and 1 y post-term had been recorded, so that the effects of weight gain before $32 \mathrm{wk}$ of gestation, between preterm birth and 3 mo post-term (early postnatal weight gain), and between 3 mo and 1 y post-term (late infancy weight gain) could be unraveled. In comparison, we tested the effect of indices of current fat mass/distribution on the lipid profile and CIMT.

\section{METHODS}

Population. The Project On Premature and Small-for-gestational-age infants (POPS) Cohort Study is a nationwide multicenter prospective follow-up study comprising $94 \%$ of all very preterm $(<32$ wk of gestation) and/or very low birth weight $(<1500 \mathrm{~g})$ infants born in The Netherlands in 1983 , in which birth, growth, and a number of other characteristics have been recorded from birth onward $(12,13)$. Gestational age (best obstetric estimate) was based on last menstrual period, pregnancy testing, and ultrasound, if necessary.

At age $19 \mathrm{y}$, all 669 living subjects with a gestational age $<32$ wk who were free of congenital skeletal deformations, Down syndrome, chromosomal abnormalities, multiple congenital deformations, or inborn errors of metabolism were approached by mail to participate in the POPS-19 study. Subjects with diabetes or familial dyslipidemia or taking thyroid hormone or systemic corticosteroids were excluded. The approval of the medical ethical committees of all participating centers was obtained for the POPS-19 study.

Study protocol. Subjects who gave written informed consent to participate were seen after an overnight fast between $0830 \mathrm{~h}$ and $1000 \mathrm{~h}$ between April 2002 and May 2003 at one of the outpatient clinics of the 10 participating centers. Assessors were blinded with respect to the perinatal characteristics of the subjects.

Venous blood was obtained after $30 \mathrm{~min}$ in the supine position. Thereafter, CIMT was measured and anthropometry performed. For the latter, subjects were measured barefoot while wearing underclothing only. All 15 assessors had received extensive training before the start of the POPS-19 study and retraining during the entire study period every $2 \mathrm{mo}$. Weight was measured to the nearest $0.1 \mathrm{~kg}$ on a balance scale, and height to the nearest $0.1 \mathrm{~cm}$ with a fixed stadiometer. Waist circumference was measured at $0.1 \mathrm{~cm}$ accuracy after gentle expiration, with a flexible tape measure. Four skinfold thickness measurements were taken in duplicate with a calibrated skinfold caliper on the left side of the body: in the triceps, biceps, subscapular, and iliacal regions. From these measurements, absolute fat mass was calculated using the equation of Durnin (14). A more detailed description of skinfold thickness measurements obtained in the POPS-19 study has been published elsewhere (15).

Laboratory analyses. Blood samples were stored at $-80^{\circ} \mathrm{C}$ and thawed only once immediately before analysis. TC and TGs were measured in a fully automated computerized laboratory system with a Hitachi 747 (Hitachi, Tokyo, Japan). HDL, LDL, ApoAI, and ApoB were measured with a turbidimetric assay on a Hitachi 911.

Carotid intima-media thickness. Image acquisition. Both left and right common carotid arteries (CCAs) were visualized in B mode using highresolution devices with linear array transducers. Five assessors from three study centers had only devices with nonlinear array transducers available for our study. Consequently, these assessors did not obtain images in the subjects who attended at their centers.

The CCA was defined as the area $2-5 \mathrm{~cm}$ proximal from the beginning of the widening of the carotid bifurcation. For the left and right CCAs, three images were obtained in an optimal longitudinal direction and frozen on the $\mathrm{R}$ wave by electrocardiographic triggering and recorded on DICOM CD, Magneto Optical Disk (MOD), or Super-VHS (S-VHS) videotape.

Analysis. Images were sent to an independent core laboratory (Heart Core BV, Leiden, The Netherlands), where the offline analysis was executed by one expert reader according to standard operating procedures. For each reading, full quality control was performed by a second reader, and a third reader did the adjudication, if necessary. Readers were blinded with respect to the characteristics of the subjects. Quality of images was considered sufficient if at least the near or the far wall of the intima-media complex could be visualized and measured over a distance of at least $4.4 \mathrm{~mm}$ in a horizontal plane in combination with the appropriate calibration factor in agreement with the specifications of the validated software.

S-VHS images were digitized first using the Vascular Imager v. 4.2.2. (Medical Image Applications) and stored in RAW format at a resolution of $512 \times 768$ pixels with 256 bits of gray levels. DICOM CD and MOD images were stored at the same resolution and grayscale. Subsequently, all images were calibrated and analyzed using the Carotid Analyzer v. 4.2.2. (Medical Image Applications). Thereafter, a digital region of interest (ROI) was defined in the CCA. The maximum ROI was selected within $2-5 \mathrm{~cm}$ proximal from the carotid bifurcation. Analysis was by automated border detection within the ROI of the near and far wall.

Standardization and reliability testing. Before the start of the POPS-19 study, assessors had received a 2-d training at the coordinating center (Leiden University Medical Center) and personal training at their own center. During the study, meetings between assessors were organized every 2 mo, and reliability of CIMT measurements of the right CCA was tested at each center in a group of four healthy young adults. Two assessors from one study center failed to obtain images of sufficient quality. Their images (of 41 subjects) were excluded from the statistical analyses. Of the remaining eight assessors, the interobserver coefficient of variation $(\mathrm{CV})$ was $6.3 \%$

Statistical analysis. Measurements of size at birth and on subsequent occasions were converted to SDSs, using Swedish references for preterm infants (16) and recently collected Dutch references (17-19), respectively. An exception was made for fat mass because of lack of population references. Early postnatal weight gain was calculated by subtracting the birth weight SDS from the weight at 3 mo SDS. Late infancy weight gain was calculated by subtracting the weight at 3 mo SDS from the weight at 1 y SDS.

Linear regression analysis was used to assess the effects of gestational age, early growth, and current size and body composition on the lipid profile and CIMT at age $19 \mathrm{y}$. To differentiate the effects of birth weight SDS, early postnatal weight gain, and late infancy weight gain on these outcomes, early postnatal weight gain was adjusted for the effect of birth weight SDS, and late infancy weight gain for the effects of both birth weight SDS and early postnatal weight gain in multivariate regression models, consistent with previous analyses in this cohort (15). Not normally distributed outcomes (TGs only) were log-transformed before statistical comparison.

All analyses were adjusted for gender and analyses with CIMT also for assessor. Analyses with early growth were repeated with adjustment for the possible confounders race (white or nonwhite), socioeconomic status $(\leq$ or $>2$ on a 6-point scale, in which 1 was lowest and 6 highest), multiple pregnancy (singleton or nonsingleton), and gestational age (as continuous as well as dichotomous ( $\leq$ or $>30 \mathrm{wk}$ ) variable).

\section{RESULTS}

At age 19 y, 669 men and women born before 32 wk of gestation were still alive and eligible for inclusion: 415 consented to participate, and 254 refused or could not be traced (Fig. 1). Three of the 415 participants met one of the exclusion criteria, 25 failed to give blood, 23 attended without fasting, and from 180, no (satisfactory) measurement of CIMT was available. Therefore, 364 and 184 individuals were analyzed with respect to the lipid profile and CIMT, respectively.

There were no significant differences in perinatal characteristics between subjects with and those without CIMT measurement (Table 1). In both groups, there was a slight female preponderance. Mean birth weight for gestational age was equal to the population reference mean, whereas weight at 3 mo and 1 y was approximately 1 SD below the population mean. The value for weight at 3 mo was missing for 25 subjects and the value for weight at $1 \mathrm{y}$ was missing for 29 . Birth weight by gestational age is plotted for each included individual in Figure 2.

At age $19 \mathrm{y}$, women had a greater waist circumference SDS and greater absolute fat mass than men (Table 2). Also, they 


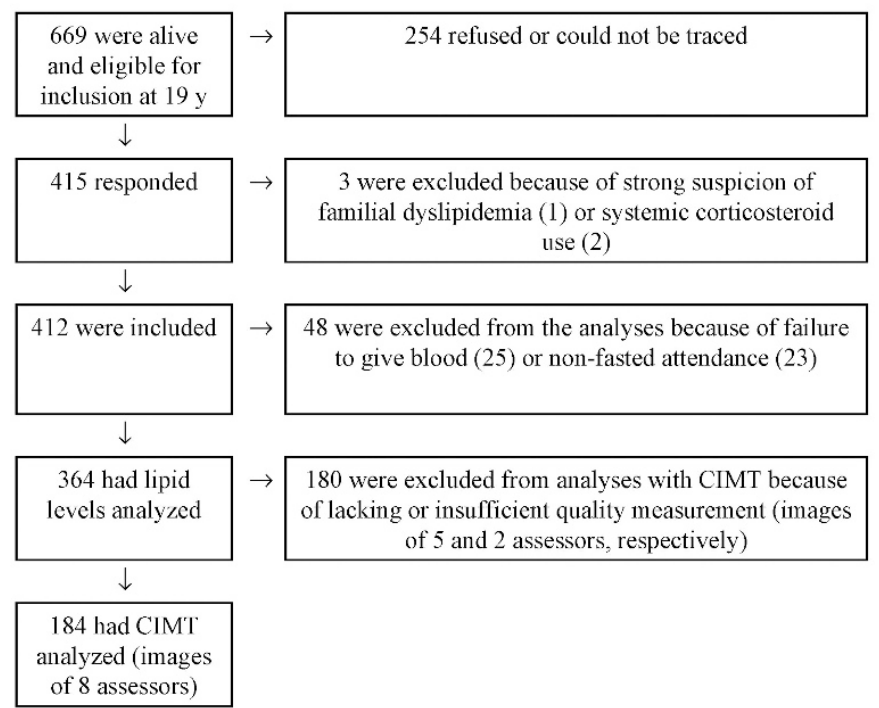

Figure 1. Derivation of study sample.

Table 1. Perinatal characteristics of the included study sample

\begin{tabular}{|c|c|c|}
\hline & $\begin{array}{l}\text { Study sample } \\
\text { with blood } \\
\text { specimen } \\
\text { only }\end{array}$ & $\begin{array}{l}\text { Study sample } \\
\text { with blood } \\
\text { specimen and } \\
\text { CIMT } \\
\text { measurement }\end{array}$ \\
\hline No. & 180 & 184 \\
\hline \multicolumn{3}{|l|}{ General characteristics } \\
\hline Males (\%) & 47.8 & 46.7 \\
\hline White $(\%)$ & 88.3 & 88.4 \\
\hline Socioeconomic status $(1-6)^{*}$ & $3.4 \pm 1.5$ & $3.6 \pm 1.6$ \\
\hline \multicolumn{3}{|l|}{ Obstetric characteristics } \\
\hline Maternal age (y) & $27.3 \pm 5.4$ & $26.7 \pm 5.8$ \\
\hline Part of multiple pregnancy (\%) & 23.3 & 24.5 \\
\hline Hypertension during pregnancy $(\%)$ & 15.6 & 19.0 \\
\hline Smoking during pregnancy $(\%)$ & 33.3 & 26.7 \\
\hline Drugs and alcohol intoxication $(\%) \dagger$ & 51.7 & 50.0 \\
\hline Prolonged rupture of membranes (\%) & 22.2 & 22.8 \\
\hline \multicolumn{3}{|l|}{ Neonatal characteristics } \\
\hline Gestational age (wk) & $29.8 \pm 1.5$ & $29.8 \pm 1.4$ \\
\hline Birth weight $(\mathrm{g})$ & $1335 \pm 331$ & $1330 \pm 341$ \\
\hline SDS & $-0.08 \pm 1.02$ & $-0.11 \pm 1.02$ \\
\hline Weight at $3 \mathrm{mo}(\mathrm{g})$ & $5208 \pm 899$ & $5100 \pm 851$ \\
\hline SDS & $-0.87 \pm 1.35$ & $-1.00 \pm 1.31$ \\
\hline Weight at $1 \mathrm{y}(\mathrm{g})$ & $8991 \pm 1242$ & $8846 \pm 1144$ \\
\hline SDS & $-0.91 \pm 1.19$ & $-1.08 \pm 1.10$ \\
\hline
\end{tabular}

Values represent mean \pm SD or percent.

* On a 6-point scale, in which 1 was lowest and 6 highest.

$\dagger$ Smoking, drinking alcohol, or using soft drugs, hard drugs, or methadone during pregnancy.

had higher levels of nearly all lipids. TGs and CIMT were not different between genders.

Effects of current size and body composition on the lipid profile and CIMT. TC, LDL, TGs, and ApoB levels and LDL/HDL and ApoB/AI ratios were each positively associated with current BMI SDS, waist circumference SDS and absolute fat mass (Table 3). HDL level was inversely associated with all these indices. ApoAI level was inversely associated only with absolute fat mass. CIMT was positively related to current height SDS. Therefore, further analyses with CIMT were also adjusted for current height SDS.

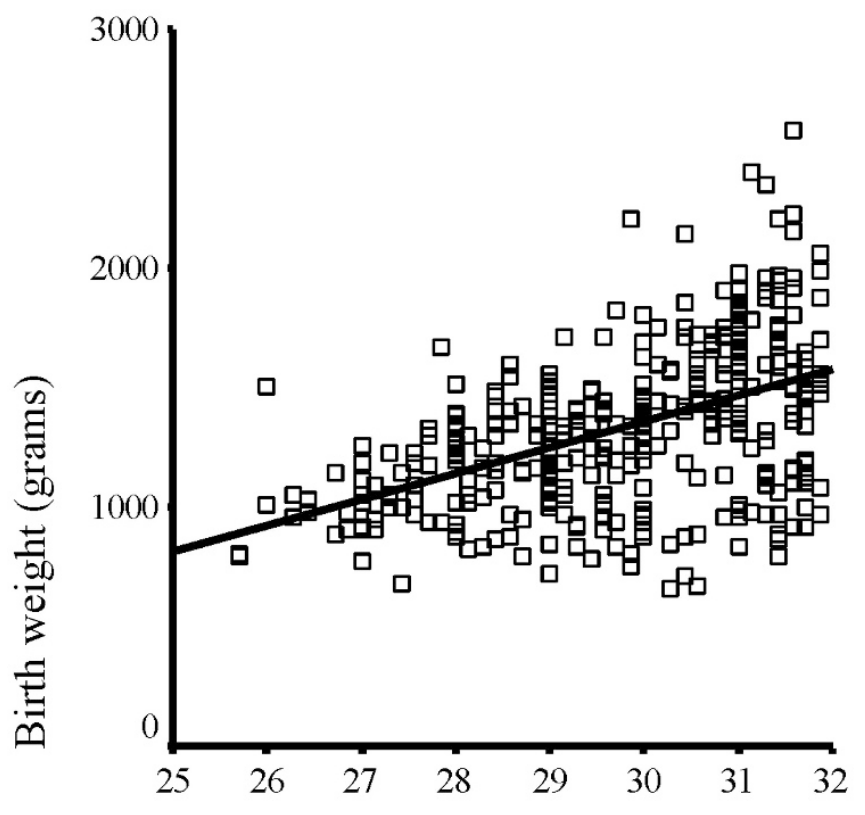

\section{Gestational age (weeks)}

Figure 2. Scatter plot: birth weight by gestational age of the 364 included subjects.

Table 2. Characteristics at age 19 years by gender

\begin{tabular}{lcc}
\hline & Men & Women \\
\hline No. & 172 & 192 \\
Body composition & & \\
$\quad$ BMI (SDS) & $0.11 \pm 1.13$ & $-0.19 \pm 1.25$ \\
Waist circumference (SDS)* & $0.22 \pm 1.09$ & $0.71 \pm 0.99$ \\
Absolute fat mass (kg)* & $11.5 \pm 5.7$ & $18.3 \pm 6.9$ \\
Lipid profile & & \\
TC (mmol/L)* & $3.89 \pm 0.75$ & $4.45 \pm 0.84$ \\
HDL (mmol/L)* & $1.19 \pm 0.23$ & $1.44 \pm 0.32$ \\
LDL (mmol/L)* & $2.32 \pm 0.67$ & $2.63 \pm 0.76$ \\
LDL/HDL ratio & $2.02 \pm 0.72$ & $1.93 \pm 0.75$ \\
TGs (mmol/L) $\dagger$ & $0.86(0.61 ; 1.23)$ & $0.80(0.55 ; 1.07)$ \\
ApoAI (g/L)* & $1.18 \pm 0.14$ & $1.37 \pm 0.20$ \\
ApoB (g/L)* & $0.67 \pm 0.18$ & $0.78 \pm 0.21$ \\
ApoB/AI ratio & $0.57 \pm 0.16$ & $0.58 \pm 0.17$ \\
CIMT $\ddagger$ & & \\
Near wall (mm) & $0.53 \pm 0.07$ & $0.54 \pm 0.07$ \\
Far wall (mm) & $0.46 \pm 0.06$ & $0.44 \pm 0.05$ \\
Mean of near + far wall (mm) & $0.49 \pm 0.05$ & $0.49 \pm 0.05$ \\
\hline
\end{tabular}

Values represent means $\pm \mathrm{SD}$.

$* p<0.001$ ( $t$ test).

$\dagger$ Median (interquartile range).

$\ddagger$ Measurements in 86 men and 98 women.

Effects of the lipid profile on CIMT. LDL and ApoB levels and LDL/HDL and ApoB/AI ratios were positively associated with CIMT (Fig. 3). After adjustment for current height SDS, the observed relationships became somewhat stronger.

Effects of early growth on the lipid profile and CIMT. The lipid profile was unrelated to gestational age, birth weight SDS, early postnatal weight gain, and late infancy weight gain (Table 4). Adjustment for race, socioeconomic status, multiple pregnancy, and gestational age (as continuous or dichotomous variable in the analyses with early growth) did not change these associations (data not shown). There was 
Table 3. Effects of current size and body composition on the lipid profile and CIMT at age 19 y

\begin{tabular}{|c|c|c|c|c|c|c|c|c|c|c|c|c|}
\hline & \multicolumn{3}{|c|}{ Height (SDS) } & \multicolumn{3}{|c|}{ BMI (SDS) } & \multicolumn{3}{|c|}{ Waist circumference (SDS) } & \multicolumn{3}{|c|}{ Absolute fat mass (kg) } \\
\hline $\mathrm{TC}(\mathrm{mmol} / \mathrm{L})$ & 357 & -0.060 & -0.136 to 0.015 & & 0.153 & 0.086 to 0.221 & 357 & 0.145 & 0.065 to 0.224 & 353 & 0.021 & 0.008 to 0.034 \\
\hline LDL (mmol/L) & 356 & -0.054 & -0.122 to 0.014 & 355 & 0.162 & 0.102 to 0.222 & 356 & 0.164 & 0.093 to 0.234 & 352 & 0.024 & 0.012 to 0.035 \\
\hline LDL/HDL ratio & 356 & -0.034 & -0.104 to 0.036 & 355 & 0.207 & 0.146 to 0.268 & 356 & 0.242 & 0.172 to 0.312 & 352 & 0.033 & 0.022 to 0.045 \\
\hline TGs $(\mathrm{mmol} / \mathrm{L})^{*}$ & 56 & -0.005 & -0.024 to 0.015 & 355 & 0.047 & 0.030 to 0.065 & 356 & 0.055 & 0.035 to 0.075 & 352 & 0.007 & 0.010 \\
\hline ApoB/AI ratio & 356 & -0.014 & -0.030 to 0.002 & 355 & 0.043 & 0.030 to 0.057 & 356 & 0.046 & 0.030 to 0.062 & 352 & 0.006 & 0.004 to 0.009 \\
\hline CIMT $\left(10^{-1} \mathrm{~mm}\right) \dagger$ & 183 & 0.071 & 0.011 to 0.130 & 182 & 0.013 & -0.046 to 0.071 & 183 & 0.044 & -0.018 to 0.106 & 182 & 0.005 & -0.006 to 0.015 \\
\hline
\end{tabular}

All analyses were adjusted for gender.

CI, confidence interval.

* Log-transformed variable.

$\dagger$ Mean of near + far wall, adjusted for assessor.

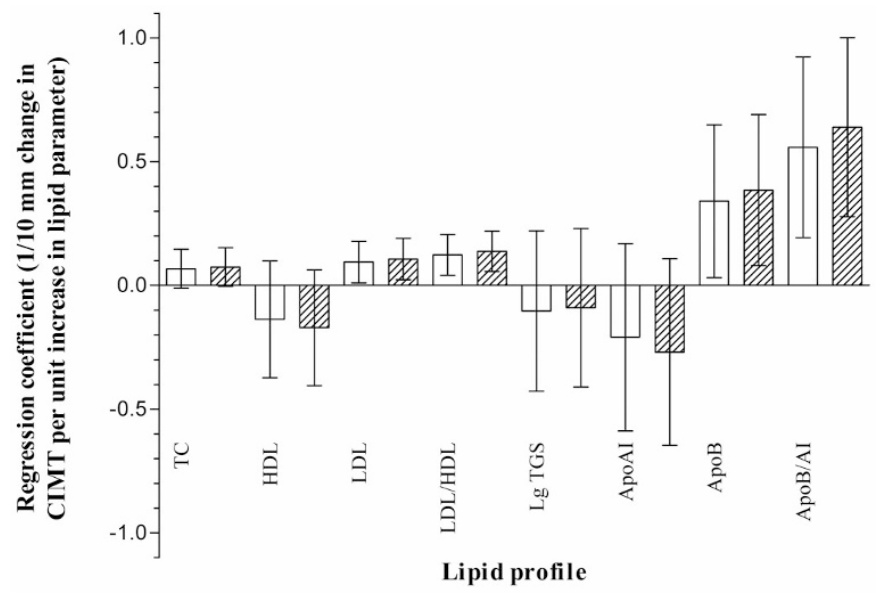

Figure 3. Effects of the lipid profile on CIMT at age $19 \mathrm{y}$. TC, HDL, LDL, and TGs in mmol/L. ApoAI and ApoB in $\mathrm{g} / \mathrm{L}$. All analyses were adjusted for gender and assessor. Hatched columns represent analyses also adjusted for current height SDS.

no evidence of interaction between birth weight SDS and gestational age on the lipid profile (data not shown).

CIMT was positively associated with late infancy weight gain: 0.091 [95\% confidence interval $(\mathrm{CI})$ : 0.005-0.178) $\times$ $10^{-1} \mathrm{~mm}$ per 1 SDS increase in weight gain (Table 3). After adjustment for current height SDS, the association lost statistical significance. Adjustment for the same possible confounders as above slightly reduced the strength of these associations (data not shown).

\section{DISCUSSION}

We studied the lipid profile and CIMT in relation to early growth and current body composition in young adults born very preterm who had been followed prospectively since birth. Our findings argue for an effect of current body composition, rather than of early growth, on the CVD risk in this specific population.

Although weak associations between birth weight and some lipid levels have been reported in full-term individuals at different ages $(8,9)$, we could not confirm such relationships in our population of 19 y olds born very preterm. Instead, we found that greater current absolute fat mass and a more central pattern of fat distribution were strongly related to a less favorable lipid profile. Also, we found that LDL and ApoB levels and LDL/HDL and ApoB/AI ratios were positively related to CIMT, while all lipid levels were within the normal range. We found no direct effects of current body composition on CIMT at age $19 \mathrm{y}$, but given the effects of current body composition on the lipid profile and of the lipid profile on its turn on CIMT, such effects are to be expected with advancing age.

Our observation that rapid weight gain in the period between 3 mo and 1 y was associated with marginally increased CIMT at age $19 \mathrm{y}$ is in contrast with findings from others in elderly men that slow growth until 1 y of age after low birth weight was associated with increased coronary artery disease risk (5). Recently, in prematurely born boys and girls aged 13-16 y, it was found that rapid instead of slow weight gain in the period between birth and 2 wk post-partum, during which an individual is normally still in utero, was associated with decreased brachial FMD (6). However, in that study, the effect of weight gain after hospital discharge on FMD had not been taken into consideration.

The observed effect of rapid late infancy weight gain on increased CIMT in our study may be causal, or, alternatively, it may be partly explained by confounding because late infancy weight gain was positively associated with current height SDS (15) and current height SDS with CIMT. Indeed, the relation between late infancy weight gain and CIMT disappeared after correction for current height SDS. It is unclear whether the loss of association was due to (appropriate) correction for a confounding variable or (inappropriate) correction for an intermediate variable in the causal pathway. However, we did not find an effect of late infancy weight gain on the lipid profile, thereby making a possible biologic basis for the effect of rapid late infancy weight gain on increased CVD risk less likely.

CIMT is a measure of structural atherosclerosis, which corresponds well with the true histologic thickness $(20,21)$. It is a strong predictor of stroke and myocardial infarction $(22,23)$. Because in our study, ultrasound images were acquired by multiple assessors $(n=8)$, associations of CIMT 
Table 4. Effects of gestational age, birth weight SDS, early postnatal weight gain, and late infancy weight gain on the lipid profile and CIMT at age 19 y

\begin{tabular}{|c|c|c|c|c|c|c|c|c|c|c|c|c|}
\hline & \multicolumn{3}{|c|}{ Gestational age (wk) } & \multicolumn{3}{|c|}{ Birth weight (SDS) } & \multicolumn{3}{|c|}{$\begin{array}{l}\text { Early postnatal weight gain } \\
(\Delta \text { SDS })\end{array}$} & \multicolumn{3}{|c|}{$\begin{array}{l}\text { Late infancy weight gain } \\
\text { ( } \Delta \text { SDS })\end{array}$} \\
\hline & No. & $\beta$ & $95 \% \mathrm{CI}$ & No. & $\beta$ & $95 \% \mathrm{CI}$ & No. & $\beta$ & $95 \% \mathrm{CI}$ & No. & $\beta$ & $95 \% \mathrm{CI}$ \\
\hline $\mathrm{HDL}(\mathrm{mmol} / \mathrm{L})$ & 364 & 0.005 & -0.015 to 0.025 & 364 & -0.015 & -0.043 to 0.014 & 339 & 0.005 & -0.021 to 0.032 & 319 & -0.020 & 0.057 to 0.016 \\
\hline LDL (mmol/L) & 363 & 0.031 & -0.019 to 0.081 & 363 & -0.001 & -0.073 to 0.072 & 338 & 0.056 & -0.009 to 0.121 & 318 & -0.021 & -0.110 to 0.068 \\
\hline LDL/HDL ratio & 363 & 0.011 & -0.041 to 0.062 & 363 & 0.015 & -0.060 to 0.090 & 338 & 0.023 & -0.043 to 0.090 & 318 & 0.022 & -0.071 to 0.114 \\
\hline ApoB (g/L) & 363 & 0.011 & -0.003 to 0.024 & 363 & -0.001 & -0.021 to 0.019 & 338 & 0.015 & -0.003 to 0.033 & 318 & -0.010 & -0.035 to 0.014 \\
\hline ApoB/AI ratio & 363 & 0.005 & -0.007 to 0.016 & 363 & 0 & -0.017 to 0.017 & 338 & 0.004 & -0.011 to 0.019 & 318 & 0 & -0.021 to 0.020 \\
\hline $\begin{array}{l}\text { CIMT }\left(10^{-1} \mathrm{~mm}\right) \dagger \\
\text { crude }\end{array}$ & 184 & -0.004 & -0.050 to 0.042 & 184 & -0.008 & -0.073 to 0.057 & 171 & 0.019 & -0.042 to 0.080 & 160 & 0.091 & 0.005 to 0.178 \\
\hline $\begin{array}{l}\text { CIMT }\left(10^{-1} \mathrm{~mm}\right) \dagger \text {, } \\
\text { adjusted for } \\
\text { current height } \\
\text { SDS }\end{array}$ & 183 & -0.004 & -0.050 to 0.042 & 183 & -0.047 & -0.117 to 0.022 & 170 & 0.002 & -0.059 to 0.063 & 159 & 0.053 & -0.039 to 0.145 \\
\hline
\end{tabular}

All analyses were adjusted for gender.

* Log-transformed variable.

$\uparrow$ Mean of near + far wall, adjusted for assessor.

with early growth may have been missed due to lack of precision. In our subjects aged only $19 \mathrm{y}$, CIMT was positively related to LDL and ApoB levels and LDL/HDL and ApoB/AI ratios, whereas all lipid levels were within the normal range. This suggests that CIMT has been measured reliably enough to detect statistically significant relationships with well-known risk factors for the atherosclerotic process. With a CV of 6.3\%, the interobserver reproducibility of CIMT measurements was similar to studies involving only two to three assessors (24-26). Thus, in our study, associations of CIMT at age 19 y with early growth were not observed, simply because they were not there.

As we had incomplete follow-up data, it may be argued that the observed associations could be biased by nonresponse. Participants did not differ substantially from nonrespondents in perinatal characteristics, nor did participants who had their CIMT measured differ from those without CIMT measurement. Nonresponse in the POPS-19 study was associated only with male gender, nonwhite race, and lower socioeconomic status (15). Men had lower levels of all lipids, except for TGs. Whites and nonwhites had comparable lipid profiles. Lower socioeconomic status was associated with a less favorable lipid profile (data not shown). However, none of these demographic factors had any effect on early growth, implying that nonresponse bias could not have substantially influenced our results.

In conclusion, our findings in $19 \mathrm{y}$ olds born very preterm argue for an effect of current body composition, rather than of early growth, on the CVD risk. Attempts to reduce the CVD risk in this specific population should focus on weight reduction in young adulthood rather than on optimizing the early growth pattern.

Participants of the Dutch POPS-19 Collaborative Study Group: TNO Quality of Life, Leiden (E.T.M. Hille, C.H. de Groot, H. Kloosterboer-Boerrigter, A.L. den Ouden,
A. Rijpstra, S.P. Verloove-Vanhorick, J.A. Vogelaar); Emma Children's Hospital AMC, Amsterdam ( J.H. Kok, A. Ilsen, M. van der Lans, W.J.C. Boelen-van der Loo, T. Lundqvist, H.S.A. Heymans); University Hospital Groningen, Beatrix Children's Hospital, Groningen (E.J. Duiverman, W.B. Geven, ML Duiverman, L.I. Geven, E.J.L.E. Vrijlandt); University Hospital Maastricht, Maastricht (A.L.M. Mulder, A. Gerver); University Medical Center St. Radboud, Nijmegen (L.A.A. Kollée, L. Reijmers, R. Sonnemans); Leiden University Medical Center, Leiden (J.M. Wit, F.W. Dekker, M.J.J. Finken); Erasmus MC-Sophia Children's Hospital, University Medical Center Rotterdam (N. Weisglas-Kuperus, M.G. Keijzer-Veen, A.J. van der Heijden, J.B. van Goudoever); VU University Medical Center, Amsterdam (M.M. van Weissenbruch, A. Cranendonk, H.A. Delemarre-van de Waal, L. de Groot, J.F. Samsom); Wilhelmina Children's Hospital, UMC, Utrecht (L.S. de Vries, K.J. Rademaker, E. Moerman, M. Voogsgeerd); Máxima Medical Center, Veldhoven (M.J.K. de Kleine, P. Andriessen, C.C.M. Dielissen-van Helvoirt, I. Mohamed); Isala Clinics, Zwolle (H.L.M. van Straaten, W. Baerts, G.W. Veneklaas Slots-Kloosterboer, E.M.J. TullerPikkemaat); Royal Effatha Guyot Group, Zoetermeer (M.H. Ens-Dokkum); Association for Parents of Premature Babies (G.J. van Steenbrugge).

\section{REFERENCES}

1. Barker DJ, Gluckman PD, Godfrey KM, Harding JE, Owens JA, Robinson JS 1993 Fetal nutrition and cardiovascular disease in adult life. Lancet 341:938-941

2. Barker DJ, Winter PD, Osmond C, Margetts B, Simmonds SJ 1989 Weight in infancy and death from ischaemic heart disease. Lancet 2:577-580

3. Rich-Edwards JW, Stampfer MJ, Manson JE, Rosner B, Hankinson SE, Colditz GA, Willett WC, Hennekens CH 1997 Birth weight and risk of cardiovascular disease in a cohort of women followed up since 1976. BMJ 315:396-400

4. Martyn CN, Gale CR, Jespersen S, Sherriff SB 1998 Impaired fetal growth and atherosclerosis of carotid and peripheral arteries. Lancet 352:173-178

5. Eriksson JG, Forsen T, Tuomilehto J, Winter PD, Osmond C, Barker DJ 1999 Catch-up growth in childhood and death from coronary heart disease: longitudinal study. BMJ 318:427-431 
6. Singhal A, Cole TJ, Fewtrell M, Deanfield J, Lucas A 2004 Is slower early growth beneficial for long-term cardiovascular health? Circulation 109:1108-1113

7. Walldius G, Jungner I 2004 Apolipoprotein B and apolipoprotein A-I: risk indicators of coronary heart disease and targets for lipid-modifying therapy. J Intern Med 255:188-205

8. Lauren L, Jarvelin MR, Elliott P, Sovio U, Spellman A, McCarthy M, Emmett P, Rogers I, Hartikainen AL, Pouta A, Hardy R, Wadsworth M, Helmsdal G, Olsen S, Bakoula C, Lekea V, Millwood I 2003 EURO-BLCS Study Group Relationship between birthweight and blood lipid concentrations in later life: evidence from the existing literature. Int J Epidemiol 32:862-876

9. Huxley R, Owen CG, Whincup PH, Cook DG, Colman S, Collins R 2004 Birth weight and subsequent cholesterol levels: exploration of the "fetal origins" hypothesis. JAMA 292:2755-2764

10. Roseboom TJ, van der Meulen, JH, Osmond C, Barker DJ, Ravelli AC, SchroederTanka JM, van Montfrans, GA, Michels RP, Bleker OP 2000 Coronary heart disease after prenatal exposure to the Dutch famine, 1944-45. Heart 84:595-598

11. Roseboom TJ, van der Meulen, JH, Osmond C, Barker DJ, Ravelli AC, Bleker OP 2000 Plasma lipid profiles in adults after prenatal exposure to the Dutch famine. Am J Clin Nutr 72:1101-1106

12. Verloove-Vanhorick SP, Verwey RA, Brand R, Gravenhorst JB, Keirse MJ, Ruys JH 1986 Neonatal mortality risk in relation to gestational age and birthweight. Results of a national survey of preterm and very-low-birthweight infants in the Netherlands. Lancet 1:55-57

13. Walther FJ, den Ouden, AL, Verloove-Vanhorick SP 2000 Looking back in time: outcome of a national cohort of very preterm infants born in The Netherlands in 1983. Early Hum Dev 59:175-191

14. Durnin JV, Rahaman MM 1967 The assessment of the amount of fat in the human body from measurements of skinfold thickness. Br J Nutr 21:681-689

15. Euser AM, Finken MJ, Keijzer-Veen MG, Hille ET, Wit JM, Dekker FW 2005 the Dutch POPS-19 Collaborative Study Group Associations between prenatal and infancy weight gain and BMI, fat mass, and fat distribution in young adulthood: a prospective cohort study in males and females born very preterm. Am J Clin Nutr 81:480-487
16. Niklasson A, Ericson A, Fryer JG, Karlberg J, Lawrence C, Karlberg P 1991 An update of the Swedish reference standards for weight, length and head circumference at birth for given gestational age (1977-1981). Acta Paediatr Scand 80:756-762

17. Fredriks AM, van Buuren, S, Wit JM, Verloove-Vanhorick SP 2000 Body index measurements in 1996-7 compared with 1980. Arch Dis Child 82:107-112

18. Fredriks AM, van Buuren, S, Burgmeijer RJ, Meulmeester JF, Beuker RJ, Brugman E, Roede MJ, Verloove-Vanhorick Wit JM 2000 Continuing positive secular growth change in The Netherlands 1955-1997. Pediatr Res 47:316-323

19. Fredriks AM, van Buuren, S, Fekkes M, Verloove-Vanhorick Wit JM 2005 Are age references for waist circumference, hip circumference and waist-hip ratio in Dutch children useful in clinical practice? Eur J Pediatr 164:216-222

20. Wong M, Edelstein J, Wollman J, Bond MG 1993 Ultrasonic-pathological comparison of the human arterial wall. Verification of intima-media thickness. Arterioscler Thromb 13:482-486

21. Pignoli P, Tremoli E, Poli A, Oreste P, Paoletti R 1986 Intimal plus medial thickness of the arterial wall: a direct measurement with ultrasound imaging. Circulation 74:1399-1406

22. Bots ML, Hoes AW, Koudstaal PJ, Hofman A, Grobbee DE 1997 Common carotid intima-media thickness and risk of stroke and myocardial infarction: the Rotterdam Study. Circulation 96:1432-1437

23. O'Leary DH, Polak JF, Kronmal RA, Manolio TA, Burke GL, Wolfson SK Jr. 1999 Carotid-artery intima and media thickness as a risk factor for myocardial infarction and stroke in older adults. Cardiovascular Health Study Collaborative Research Group. N Engl J Med 340:14-22

24. Belcaro G, Geroulakos G, Laurora G, Cesarone MR, De Sanctis, MT, Incandela L, Barsotti A 1993 Inter/intra-observer variability of carotid and femoral bifurcation intima-media thickness measurements. Panminerva Med 35:75-79

25. Sidhu PS, Desai SR 1997 A simple and reproducible method for assessing intimalmedial thickness of the common carotid artery. Br J Radiol 70:85-89

26. Kanters SD, Elgersma OE, Banga JD, van Leeuwen, MS, Algra A 1998 Reproducibility of measurements of intima-media thickness and distensibility in the common carotid artery. Eur J Vasc Endovasc Surg 16:28-35 